Anuario da Facultade de Dereito da Universidade da Coruña

Vol. 21 (2017), pp. 435-438

ISSNe: 2530-6324 || ISSN: 1138-039X

DOI: https://doi.org/10.17979/afdudc.2017.21.0.3290

\title{
STRONG, S.I.; FACH GÓMEZ, K.; CARBALLO PIÑEIRO, L., Comparative Law for Spanish-English Speaking Lawyers. Legal Cultures, Legal Terms and Legal Practices / Derecho comparado para abogados anglo- e hispanoparlantes. Culturas jurídicas, términos jurídicos y prácticas jurídicas, Edward Elgar Publishing, Cheltenham/Northampton, 2016, 672 págs.
}

\author{
GABRIELA A. OANTA \\ Profesora contratada doctora (acreditada Profesora Titular de Universidad) de \\ Derecho internacional público y Relaciones internacionales \\ Universidade da Coruña
}

El libro Comparative Law for Spanish-English Speaking Lawyers. Legal Cultures, Legal Terms and Legal Practices / Derecho comparado para abogados anglo- $e$ hispanoparlantes. Culturas jurídicas, términos jurídicos y prácticas jurídicas, que es objeto de atención en la presente recensión, es fruto de la original labor realizada por tres profesoras de Derecho (S.I. Strong, Katia Fach Gómez, y Laura Carballo Piñeiro) procedentes de tres Universidades diferentes de Estados Unidos de América y de España (Universidad de Missouri, Universidad de Zaragoza, y Universidad de Santiago de Compostela).

Las autoras de este libro se han propuesto concretar un ambicioso proyecto humano y profesional, esto es escribir una obra totalmente bilingüe - en los dos primeros idiomas de mayor difusión internacional (inglés y español) - dedicada, desde una perspectiva del Derecho comparado, a las culturas jurídicas, empresariales y sociales, sin perder de vista en ningún momento que su trabajo será manejado sobre todo por personas con formación jurídica con un buen dominio del inglés (para los hispanófonos) o del español 
(para los anglófonos). Es de justicia destacar que para la realización de este libro se han utilizado los Ordenamientos jurídicos de los Estados Unidos de América y del Reino Unido en las partes del libro redactadas en inglés, y a los Ordenamientos jurídicos de España y de México en las otras partes del libro, que fueron redactadas en español. Se trata, sin duda, de un enfoque novedoso, nunca antes abordado ni en la doctrina hispanófona ni en la anglófona, pero que encuentra una perfecta justificación en el actual rasgo globalizador de la Sociedad internacional contemporánea.

El presente libro se organiza de la siguiente manera: después de una breve Introducción en la que se presenta también una primera aproximación a la expresión "culturas jurídicas, empresariales y sociales" - que, de hecho, constituye una parte del título de este libro - las autoras presentan de un modo ordenado y sistemático las fuentes del Derecho (Sección II), determinadas áreas jurídicas específicas (Sección III), y las cuestiones de la práctica jurídica (Sección IV). Este excelente trabajo finaliza con una parte dedicada a ejercicios prácticos (Sección $V$ ), que se suman a los test de autoevaluación que pueden encontrarse al final de muchos apartados tratados en este libro. Las numerosas y complejas cuestiones tratadas en cada uno de los epígrafes de estas Secciones son presentadas de una manera sencilla a fin de ayudar a los abogados bilingües a identificar las diversas instituciones jurídicas tan importantes para el ejercicio de su profesión.

Destaca el método empleado por las autoras para presentar todas estas cuestiones complejas, y cumplir así con el objetivo general de este libro, esto es escribir una obra totalmente bilingüe. En este sentido, cabe mencionar que cada cuestión tratada sigue la misma lógica, siendo una muestra viva de la constante preocupación de las autoras por presentar el trabajo realizado de la manera más sistematizada posible, a saber: en primer lugar, se presenta el tema abordado en inglés; en segundo lugar, se identifican las palabras claves en la materia, en inglés; en tercer lugar, se realiza un resumen tanto en inglés como en español del tema tratado; en cuarto lugar, se explica en español el tema objeto de estudio; y, en quinto lugar, se indican en español las palabras clave ya mencionadas en inglés.

Los aspectos referidos a las fuentes del Derecho - plasmados en la Sección II - ocupan la mayor parte del presente libro. Ello es perfectamente justificable al abordarse en ella tantas cuestiones relevantes propias de las fuentes del Derecho. Así, se presentan los principios básicos de Derecho comparado, la legislación, las decisiones de la judicatura y otros tribunales, y la doctrina. Son de destacar, también, los ejercicios de autoevaluación incluidos al final de los epígrafes dedicados a la legislación, la jurisprudencia, y a la doctrina, respectivamente.

La Sección III se estructura en torno a dos grandes categorías jurídicas, esto es el Derecho sustantivo y el Derecho procesal, respectivamente. Por lo que se refiere al Derecho sustantivo, las autoras de este libro se centran sobre todo en aquellas ramas de Derecho que de antemano parecen más significativas para los abogados bilingües, a saber: el Derecho constitucional, el Derecho de obligaciones y contratos, el Derecho 
penal, el Derecho de extranjería, el Derecho societario y de la competencia, y el Derecho internacional público. En cuanto al Derecho procesal, las autoras presentan las distintas facetas de esta rama del Derecho, haciendo distinción entre el Derecho procesal civil (incluidas las reglas probatorias), el Derecho procesal penal (incluidas las reglas probatorias), y las reglas de procedimiento y prueba en arbitraje comercial internacional y de inversiones, respectivamente.

Las autoras han hecho una apuesta arriesgada a la hora de identificar y tratar, en la Sección $I V$, las cuestiones más relevantes a su entender resultantes de la práctica jurídica. En este sentido, se presentan aquellas cuestiones prácticas que un abogado bilingüe necesitaría conocer a la hora de ejercer la abogacía en otro país con una tradición cultural jurídica diferente. Así, se muestran: los escritos dirigidos a los tribunales de justicia, arbitrales y otras instituciones (haciéndose especial hincapié en las condiciones para presentar una demanda, los tipos concretos de escritos judiciales, arbitrales y otras institucionales, etc.); los documentos transaccionales (en relación con la negociación intercultural, los procedimientos de ñas transacciones bilingües, las cuestiones estructurales referidas a contratos transfronterizos y otros documentos utilizados en la práctica transaccional, así como las disposiciones clave en los pactos transfronterizos); y la correspondencia externa e interna y los dictámenes (como, por ejemplo, las típicas convenciones formales a la hora de redactar escritos en las jurisdicciones hispanohablantes, y las comunicaciones internas y externas en las jurisdicciones hispanohablantes). Nos parecen muy útiles los documentos modelo incorporados por las autoras en relación con cada una de las cuestiones más significativas identificadas y tratadas en la presente Sección, así como los ejercicios de autoevaluación que permitirán a los usuarios de este libro examinar el nivel de sus conocimientos y comprensión de las cuestiones tratadas en esta parte del libro.

El presente libro finaliza con la Sección $V$ que se compone, por un lado, de sendos ejercicios prácticos (dedicados a la disputa arbitral, así como a la transacción jurídica) y, por otro lado, de las contestaciones a los test de autoevaluación incluidos en los distintos epígrafes de este libro.

Sin duda, todo ello es una muestra viva del importante conocimiento práctico de las autoras de este libro de los términos y los conceptos jurídicos esenciales tratados en este trabajo conjunto, apoyado, además, en una gran labor de recopilación, investigación y análisis, realizada probablemente durante varios años, de un significativo número de fuentes doctrinales y jurisprudenciales. Consideramos que es de justicia señalar que, si bien las autoras se refieren en numerosas ocasiones a la pertinencia de las cuestiones abordadas para el ejercicio de la profesión de abogado por parte de personas bilingües, este libro se perfila como una herramienta muy útil también para los estudiantes y profesores, que quisieran comprender mejor el complejo mundo del Derecho en inglés (para los hispanófonos) y en español (para los anglófonos), respectivamente. Además, estimamos que la publicación de este libro se concreta en un momento muy oportuno, favorecido por el auge de la implantación de un "Programa en Inglés" en un gran número de Facultades de Derecho existentes en el Sistema Universitario Español que 
hacen de este libro un instrumento imprescindible para la impartición y el estudio de diversas asignaturas de Derecho en el marco de dichos Programas.

En resumidas cuentas, se trata de un libro muy oportuno, original y con un alto valor práctico, que constituye una excelente contribución para el estudio del Derecho bien en inglés (para los hispanófonos) o bien en español (para los anglófonos), y que contiene un material de gran riqueza práctica y documental, cuyo manejo resultará muy útil y de obligada lectura para estudiantes, profesores, abogados bilingües y otros ejercientes del mundo del Derecho, a fin de adentrarse en el complejo universo del Derecho comparado. 